\title{
Governance of migratory flows from establishment of identity and agenda of occupational health
}

\author{
Francisco Espinoza-Morales \\ Héctor Daniel Molina-Ruíz \\ Rigoberto Sánchez-Rosales* \\ Arturo Sánchez-Sánchez \\ Cruz García-Lirios* \\ Universidad de Sonora, México \\ Universidad Autónoma del Estado de Hidalgo, México \\ Universidad Autónoma del Estado de México, México* \\ Universidad Autónoma de Tlaxcala, México
}

\begin{abstract}
The governance of migratory flows, understood as a system of co-management coresponsibility between institutional and private, political and social actors with respect to their identity and occupational health is addressed in the present nonexperimental, exploratory and cross-sectional work with a non-probabilistic sample selection of 147 former migrants from central Mexico. From a structural model seven factors were established regarding framing, demands, resources, risks, opportunities, capabilities and employment. Based on the literature consulted, the limits, scope and lines of research aimed at deepening the effects of the variables and factors in an intercultural scenario are noticed.
\end{abstract}

Key words: Migration, governance, acculturation, interculturalism, identity, agenda. Gobierno de los flujos migratorios a partir del establecimiento de identidad y la agenda de la salud ocupacional.

\section{Gobierno de los flujos migratorios a partir del establecimiento de identidad} y la agenda de la salud ocupacional

\section{Resumen}

La gobernanza de los flujos migratorios, entendida como un sistema de gestión de corresponsabilidad entre los actores institucionales y privados, políticos y sociales con respecto a su identidad y salud ocupacional, se aborda en el presente estudio no experimental, exploratorio y transversal con una selección de muestra no probabilística de 147 ex migrantes del centro de México. A partir de un modelo estructural, se establecieron siete factores relacionados con el marco, las demandas, los recursos, los riesgos, las oportunidades, las capacidades y el empleo. Sobre la base de la literatura consultada, se observan los límites, el alcance y las líneas de investigación destinadas a profundizar los efectos de las variables y los factores en un escenario intercultural.

Palabras clave: Migración, gobernanza, aculturación, interculturalidad, identidad, agenda.

Recibido: 23 de febrero de 2019

Aprobado: 27 de marzo de 2019 


\section{INTRODUCTION}

his work is part of the Social Work discipline, an area of migratory studies and includes concepts from organizational psychology such as identity, the sociology of work as occupational health, labor economics such as acculturation and migrant communication as the agenda bilateral (Sánchez et al. 2018).

The purpose of this study is contrast perceptual factors inherent former inmigrants. Immigrants refers to the difference between the number of people expelled in an emerging economy compared to the number received in a developed economy (Zong and Batalova, 2019), who traveled to the United States, settled economically and decided to return to their place of origin once the opportunities, or, their capacities were reduced by economic crises or public insecurity (Garcia, 2018).

In the case of immigrants from Mexico who operate in the United States, they represent 25 percent (11.3) of the total of immigrants (44.5 million), although their upward trend was reduced from 2016, losing close to 300 thousand for 2017.

However, Mexican migrants now have knowledge of higher education and mastery of a percentage of English with respect to previous flows (see Figure 1).

Figure 1: Migratory flows from Mexico to the US

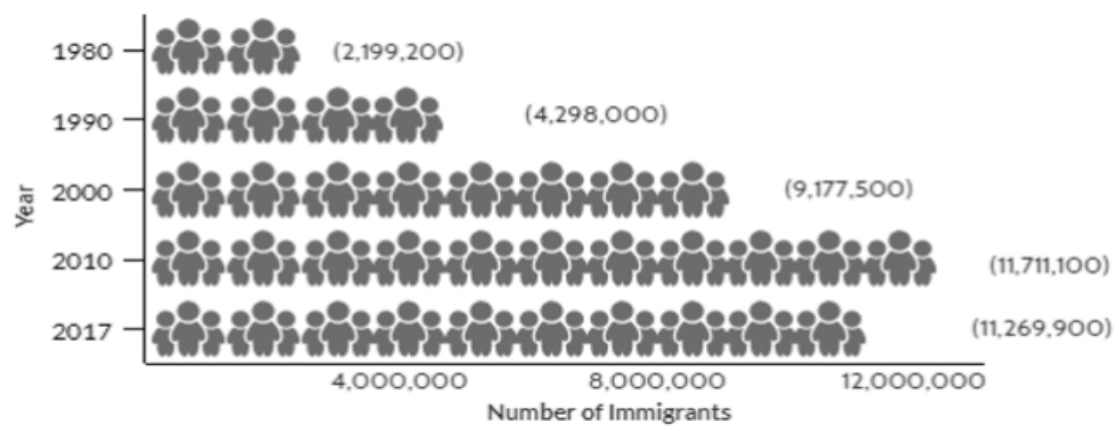

Source: US Census Boureau (2017). 
The working age (18 to 64 years) average of Mexican migrants was 43 in 2017, 45 for the rest of migrants and 36 for natives of the United States (See Figure 2).

Figure 2: Prevalence of working age among migratory flows in the US

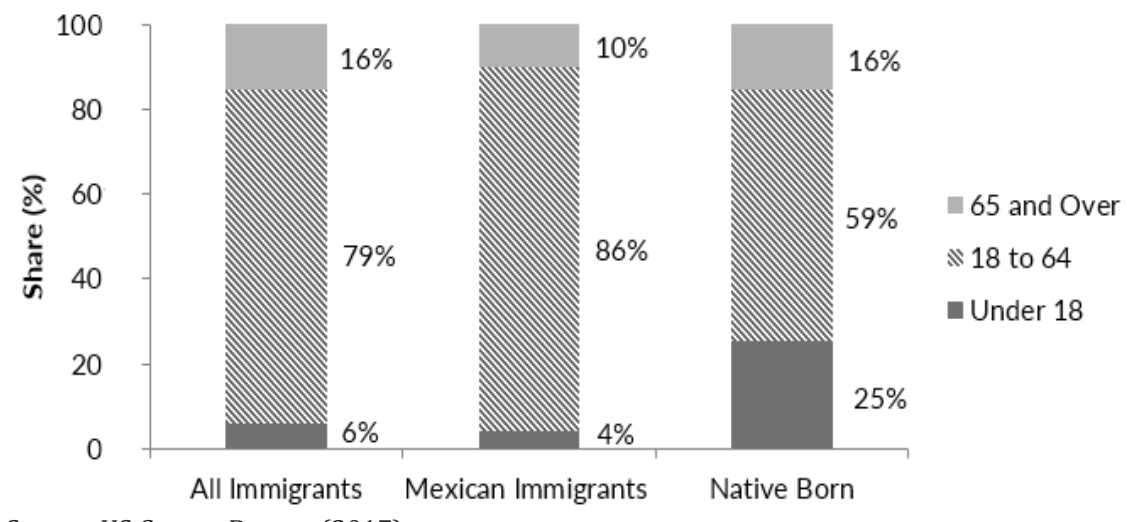

Source: US Census Bureau (2017).

In that same year, 55 percent of Mexican immigrants lacked a high school certificate, only seven percent had a bachelor's degree, explaining the concentration of the workforce in the service sector (see Figure 3).

Figure 3: Migratory flows and occupational natives

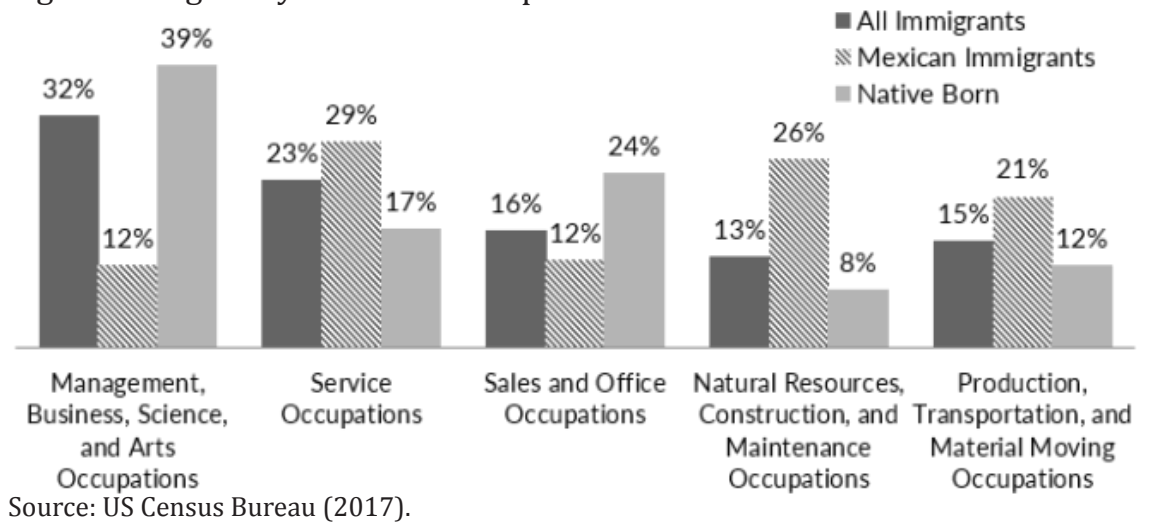

The governance of migratory flows, for the purposes of this paper, from organizational psychology refers to a system of co-management 
and co-responsibility between talents and leaders with respect to the demands of the outlook and internal resources, but this model centered on identity as The engine of the climate of relationships, supports, tasks and innovations does not always include the occupational health that the sociology of work has revealed as a consequence of the imbalance between the requirements of the environment and the capacities of organizations (Aldana et al. 2019).

Well, occupational identity and occupational health seem to coexist in a scenario of adaptation and assimilation of the requirements of the receiving environment in relation to migratory flows. It is a context of acculturation that in its most advanced dimension refers to a multiculturalism in which the migratory flows conform to the values and norms of natives, but such an instance would not be possible without the dissemination of a propaganda of the rectory of the State as axis of expulsion and reception of migratory flows that crystallizes in an agenda (Delgado et al. 2018).

In essence, the landscape of the governance of migration flows involves different levels, categories and variables, which revolve around identity, health, acculturation and the bilateral agenda between expelling countries and host economies.

\section{THEORY OF THE GOVERNANCE OF MIGRATORY FLOWS}

The theoretical frameworks that explain the governance of migration flows focus on the establishment of an agenda which uses identity as the axis of migration, but circumscribed to a context of economic acculturation with a broad impact on occupational health since the type of work determines the quality of life and this to the working condition (Sánchez et al. 2018).

There are four laws that detail the differences between migrants and origins with skills, productivity, marginality and utility in the field. This is the Law of Distinction with a work arrangement that promotes equal opportunities, but differentiation in terms of quality and work capacity, for example, the unequal distribution of benefits. If the workers have more possibilities of being able to consume more, then their degree of satisfaction will be reduced to the acquired goods and services as in the Law of Marginal Utility. 
Now, in the process of work and consumption, the point of inflection will prevail in which some variable ceases to be continuous and becomes discrete as the skill of the worker, promoting a slowdown in growth as explained in the Law of the Diminishing Marginal Returns (see Figure 4).

Figure 4: Increasing or optimistic returns, constant or expected returns and decreasing or pessimistic returns

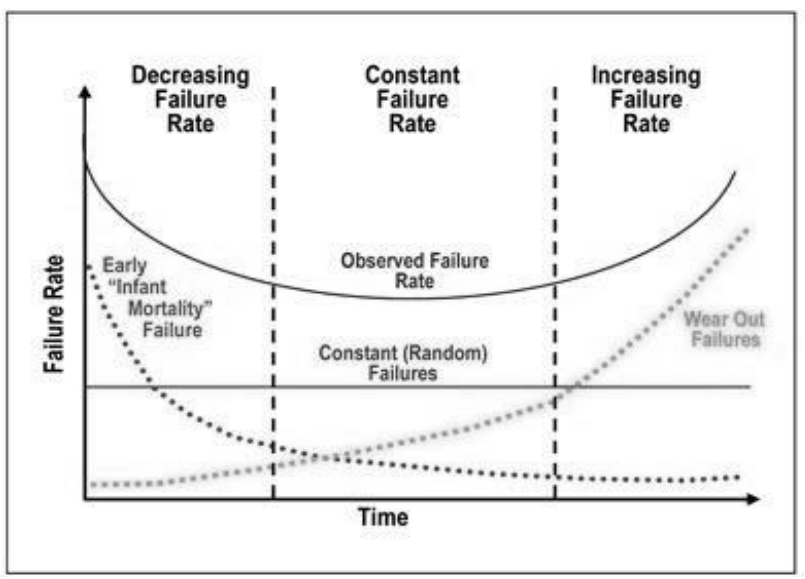

Source: Fonseca, Valenzuela, Perrand and Casulo (2017).

Lastly, the Law of Socialist Economics that raises the satisfaction of the needs and expectations of workers in a regime of equal opportunities based on social production.

In short, the four laws warn the relationship between tangible and intangible assets in a productive organization that will be distinguished by the degree of productivity, scalability and satisfaction, since an intangible asset such as experience and knowledge of migratory flows will provide a greater evolution of the same flow to reach a greater position in the service sector where its workforce prevails and the consequent transformation of the local market in the creation of knowledge for the case of the economy 4.0 or the production of technology that designs, generates and manages more technology.

Perceptions of insecurity and risk of television audiences with respect to users of other media. The increase of fear, worry, anger, indignation or uncertainty is the result of excessive exposure to television programs that guide the authoritarian values of its viewers 
in order to justify public safety policies that reduce the freedom of choice to its minimum expression (Guardiola et al. 2010).

The enhancement of issues relating to public safety in personal agenda, at first instance and on the public agenda in the final instance. In this sense, the exacerbated dissemination of topics in the media generates a list of surrounding issues in the public opinion and its public discussion. Thus, if the issues are related to violence, then the hearings will justify the programs for the prevention and fight against crime, but if the issues allude to a public peace scenario, then the users of the media will assimilate those programs of civic education (Guardiola et al. 2010).

The media of communication highlight specific attributes of the facts to guide the public opinion regarding causes and effects of the same events. In this sense, a message from the media has been framed in such a way that the recipients will immediately identify the causes of these events when associating with certain political or economic actors (Guardiola et al. 2010).

There are significant differences between the migrant self-concept and identity of the group to which it belongs or wants to belong in a situation of exclusion. He points out that there are differences beyond the groups and their identity processes, asymmetric relations between urban spaces and rural areas suppose complementary scenarios of discursive interaction. In this sense, identity is constructed from the exchange of ideas rather than goods. It should be noted that dialogue is developed as a contest of ideas rather than as a consensus (Pacheco, 2013).

Prejudice, discrimination, xenophobia, racism or exclusion of indigenous people regarding migrants as these are seen as usurpers of resources, goods and services that seniority rights are attributed to the natives of a territory to the detriment of the rights of a group external to their uses and customs (Bahamonde, 2013).

Economic, political, social, educational, technological, scientific and digital divides between groups of high economic status with respect to margin groups excluded are explained ideologies gaps between the sectors when they are attributed a power that will influence the actions of institutions with respect to favoring the practices of the groups in power and inhibiting the development opportunities of excluded, vulnerable or marginalized groups. As a result, differences between adults with respect to children, young people or older adults are ge- 
nerated, as well as asymmetric relationships between men and women (Bahamonde, 2013).

Suggests that the individual has, in its powers; skills, knowledge and values, the tools to determine your lifestyle and immediate future. It raises that the rent is a central concept in the explanation of the personal human development since the individual has the possibility of increasing his income derived from the rent of his capacities. This assumes that human capital is oriented to the relationship between opportunities and capabilities. When opportunities are zero and capacities are non-existent, then a business promotion policy is justified. An increase in opportunities combined with a decrease in skills, or a reduction in opportunities in reference to the increase of skills, supposes a human capital that is devalued or inhibited in its development. However, an amplification of opportunities and intensification of capacities enhances the human capital of a society (Farraguti, 2012).

It is a model in which labor demands generate stress and labor resources favor happiness. In this way, the motivation of the individual is focused on what the group expects from him in reference to his abilities. Often, the individual develops responses that increase or decrease their work pressure. This is the case of the demands of overload, limit objectives, concentration, precision, attention, decisions, empathy, emotions, conflicts and insecurity. In the case of resources, they refer to climate, technology, feedback, coaching and flexibility (Salanova and Schaufeli, 2009).

Work as a stage of relationships in which individuals, demands and resources are interrelated such that tend to unbalance as individual capacities are often overwhelmed by the technology or, the demands do not follow a logic of technological development or professional training. That is why in the labor practice, individuals adjust their capacities to the scarcity of resources while they keep the increase in demands (Salanova and Schaufeli, 2009).

Autonomy and the individual's ability to understand their intrinsic work motivation. As is known, the demands are asymmetric to the resources. In this sense, capacities play a mediating role in the differences between demands and resources, but this action is gestated from autonomous decision making and the development of skills, knowledge and values related to the individual rather than the group to which he belongs or wants belong (Salanova and Schaufeli, 2009). 
The workplace is increasingly uncertain; individuals tend to preserve resources based on expected demand. This impacts labor relations because the individual rather than joining a group, is associated with individuals who in the future may help him to respond to future demands. Or, other individuals specify their functions up to a degree of optimization that will allow them to supply the commitments that the demands involve them to fulfill in time and form. As demands intensify and resources become scarce, individuals tend to emphasize internal alliance external to the organization (Salanova and Schaufeli, 2009).

\section{EXPECTATIONS WORK}

Economic factors related to crisis, unemployment, migration, employment and prosperity link theoretical frameworks that explain educational and social factors around which research has been carried out that poses to the dynamics of groups as the predominant scenario of explanation of the journey and migrants' stay as well as the return and reintegration of former migrants (Mercado and Piña, 2010).

Migration is a central theme in the agenda of sending and receiving countries since it is involved with economic and demographic factors. This is the case of global investment flows in which it is possible to observe a capture of Foreign Direct Investment (FDI) in the United Kingdom (USD 50 billion), the main recipient of migrants (Guardiola et al. 2010).

However, FDI is also concentrated in the United States $(25$ million USD and 9 million migrants in the last decade), Ireland, Spain and Sweden. In reference to Latin America, the United States receives more migrants from Mexico (from 150 to 275 thousand migrants from 1999 to 2010) with respect to the countries of Central America. (Fernández, 2011).

The migration from Mexico to the United States is explained by the level of unemployment in the sending countries and employment opportunities in the host country. It is possible to observe that the state with the highest number of expulsions is Coahuila (5.5 percent of total migrants) and San Luis (five percent). In this sense, the Huasteca region expelled a significant number of migrants with respect to other state entities. Remittances, as an effect of FDI, unemployment and migration, went from 3 billion USD in 2006 to 2.5 billion in 2008 (Ten, 2010). 
Migration on economic regional concert appears to be a link in the economic chain is determined by FDI and has its main effect on remittances, but in the particular case of migration in Xilitla, La Huasteca of San Luis Potosi (Mexico), seems to be imbricated in a system of opportunities and capacities that not only affect employment and occupation, but also involves a series of social factors and that the groups in which the former migrants are inserted also influence their employment situation (Castro and Rosero, 2011) .

A review of the state of knowledge of migration in Central America, Mexico and the United States. The literature mentioned that migration was an adaptation of migrant flows in central areas of their economy, but there were indications that migrants assimilated the culture that received them, even the most critical jobs warned of a multicultural identity that descendants of migrants already selected not to adjust to the imponderables, but to transform and innovate their environment (Sosa and Zubieta, 2012).

The migratory flows far from indicating a spurious Local Development manifested a spiral of growth in which not only the migratory phenomenon, as the literature reports, contributes to the endogenous development, but it stagnated to such an extent that the prosperity is no longer indicated by the remittances, but by the investments that the demarcation has registered in the last years once it has been designated the category of Magical Town and with it the governmental support, combined with the local or surrounding investment, has generated when least expectations of welfare and prosperity for this municipality (Bahamonde, 2013).

However, despite the fact that prosperity is evident, whether by federal, state, local or private investment, the present work is based on analyzing the determinants of the job search of residents who were migrants yesterday and are now entrepreneurs. The migratory flows in their media, social, labor and identity dimensions consider that investment impacts the labor capacities of migrants. As demands increase and resources decrease, labor competencies are intensified to respond to the group dynamics that take place in organizations. The relations between demands, resources and individuals seem to be circumscribed to mediatic, perceptual and behavioral factors. This is because migration is a complex phenomenon that transfers the impact of foreign investment on the dynamics of the organizations in which migrants are inserted. Consequently, the theories that explain the re- 
lations raised allude to a series of dependency relationships among demands, resources and capacities (López, 2013).

The relationship between perceptual factors regarding job search, suppose Perceptual to establish dependency relationships between these variables and job search factors. The indirect relationship between the perception of framing and the search for employment based on the intermediation of the perception of demands, resources and opportunities. That is, the time and space of migration is often perceived as two axes in which the demands and resources of the local market are lower compared to the international market. In this way, opportunities, if the demands and resources are considered in a given time and space, are abundant or scarce (Delgadillo et al. 2013).

The perceptual bias that is incurred when comparing two economies, one expelling and one receiving migrants, would derive from the formation of public opinion by the media. The relationship between framing perceptions and the job search reveals to the perception of risk as the fundamental variable for such a question. The media justify political authoritarianism asymmetry between risks and opportunities when seeking employment is also explained. That is, if expectations of uncertainty are transmitting the "cultivation" of insecurity and authoritarianism, then migrants seeking employment may perceive greater opportunities in jobs that pose a risk to resident workers. On the contrary, the migrants themselves may be perceived as a threat to the labor interests of the residents and, therefore, be underestimated or even, based on these attributions, the citizen opinion can justify the working conditions of the migrants (Mora et al. 2013).

Being a central theme in the agenda of the recipient countries, migration implies an intensive diffusion of the media that seek to influence the public agenda and with it in the political agenda regarding the criminalization or legalization of migration, or xenophobia or multiculturalism. The perception of framing of employment, being a consequence of the establishment of issues related to migration, would generate expectations of risk and opportunity. As the demands and resources of the expelling society and the host society of migrants intensify, the risk and perceived opportunities increase (Berrou and Combaunous, 2012).

However, the public opinion of the host country not only discusses the exclusion or inclusion of migrants, it also generates xenophobic or inclusive discourses based on attributions that the media make to mi- 
grants and their countries of origin. Once the media have "cultivated" the public insecurity that migration poses for the countries that receive migrants, once they have established the deportation or legalization of migrants as their axis of discussion and once they have associated the wave of violence at the arrival or stay of migrants, the job search is, now more than ever, based on risks rather than opportunities. It is a scenario in which options are reduced to their minimum expression while the labor market becomes informal for migrant labor.

In this scenario, identity is a preponderant factor to explain the socialization, adaptation, assimilation and selection of migrant labor. Identity, in contrast to spaces, times, diffusions, themes or frames, is the primary factor in explaining the relationship between the perception of a work environment and the search for employment. Migrants do not move for economic or media platforms, but by family networks that determine the exclusion or inclusion of a migrant in an organization. It is a series of decisions that the individual carries out before inserting himself into the dynamics of a for-profit organization or group.

However, imponderables such as discrimination, xenophobia, exclusion or racism are inherents to the dynamics of a group. To identity is essential to explain the passage, establishment and return of the migrant workforce factor. Identity is associated with the perception of insecurity while it is a homogeneous factor among migrants and original residents. The differences between the migrant group and the resident group are that identity makes them differentiate as hegemonic groups with respect to their counterparts (Martínez, 2012).

However, the possibility that the economic system high-status groups or the political system inhibits the participation of migrants and exacerb and differences with respect to resident citizens. The differences between the groups is inexorable to their capabilities. Rather, the asymmetric relations between residents and migrants at the time of seeking employment is generated from the social structure of both the expelling country and the recipient country. That is, in both countries institutions tend to block initiatives that favor the free movement of people and favor the segregation of groups because of their economic, ethnic, educational, professional and labor conditions.

If the institutions play in favor of one of the actors involved while undermining the capacities of the migrant sector, then we are witnessing a scenario in which the capacities will determine the balance 
between the groups since labor, health or educational exclusion is often counteracted for initiatives that arise from dissident groups to the system. The influence of the structure on the individual, regardless of spaces, times, means, themes, framings, identities, groups or institutions, the individual is trusting to receive more and more demands and respond with fewer and fewer resources (Mora et al. 2013).

The equation of migration in an opposite way. In principle, he argues that migration is not the result of a context of economic crisis or public insecurity, but rather, it is the effect of a series of capabilities that distinguish migrant groups from static or resident groups. Opportunities and capabilities explain the relationship between the framed perception of the facts and the search for employment. Migrants can be "cultivated" to accept insecurity and adopt political authoritarianism as a single solution, they can even be assumed to be a danger to resident groups, or to believe that institutions exclude them to care for residents, but it is a From their capacities they manage to be selected to assimilate, adapt and even socialize their skills, knowledge and values with the groups that exclude them, within the framework of the organizations that marginalize them or the society that conceives them as vulnerable groups. This is because migrants adjust their expectations and capacities to the demands and resources that are around them (Caballo et al. 2006).

Individual capacities are personal resources that migrants employ regardless of public security, media influence, institutions or groups they want to belong. The demands and resources are a first instance of mediation between reality spread by the media and job search. These are two factors that delimit the individual action in reference to the groups with which it interacts. This means that the migrant individual is able to compensate for the imbalance caused by the increase in demands and the reduction of resources with skills and knowledge, but without assuming networks of trust or cooperation (Sosa and Zubieta, 2012).

In a context of competitiveness, the lack of technology means the intensification of efforts and therefore the decrease in the quality of processes. Knowledge management looms over those groups that manage to establish a balance. In order to achieve the established goals and objectives, the organizations supplement the scarcity of re- 
sources with autonomous labor relations, trust, commitment and motivation (Manktelow, 2014).

Labor autonomy not only implies the possibility of organizations forming a vertical organizational structure, but also the option that knowledge management is not decided by management when creative personnel require a wide margin of maneuver. In this sense, the conservation of resources would be a symptom of the collaborative and innovative networks that underlie work autonomy.

In essence, the anticipation of creative and innovative groups in situations of scarcity or risk refers to the fact that the migrants have experienced different scenarios and are closer to adapting to the changes because they assimilate alternative processes that, when they are socialized, delimit their margin of action and systematize their responses influencing groups that consider them external (Ramos, 2013).

The analysis of individual capacities rather than group identities, media biases or economic spaces assumes that individuals oscillate between a resource availability lower than the demands of the environment. It is about work autonomy to indicate that individuals form networks of trust, commitment and satisfaction when the organization gives them a wide margin of maneuver. On the contrary, the scarcity of resources plus the restriction of freedoms seems to be a barrier that hinders the emergence of alternatives because it inhibits the transfer of information between the groups.

In this organizational framework, migration is a phenomenon that emerges as a justification or solution to the imbalance between demands and resources. In the first case, knowledge management is restricted to migrant labor groups simply because they attribute inferior knowledge or poor training. In the second case, the quality of production is influenced by the excessive contribution of migrant groups within the organization. Migrant labor that operates outside the established standards for workers residing in the host country is condemned to substitute the automation of processes (Robles et al. 2016).

The relationship between information biased by the media and the search for employment in migrant groups in organizational settings alludes to processes such as; migration, mediatization, identity, capacities, demands and resources, also supposes perceptions around these processes. It is about six appreciations around information from at least two spaces, times, identities, groups, demands, resources and asymmetric capacities. In this way, spaces can be perceived as scenari- 
os of opportunity or risk, times as distances in which closeness or distance encourage the search for employment. In the case of identity, this may be perceived as unfair or just in reference to groups that in turn are perceived as threatening or trustworthy.

However, the Findings do not always coincide. Moreover, the selection of ten studies related to the state of knowledge makes many of the assumptions made unlikely. It is possible to conceptually relate the selection of the ten studies with some exposed grounds. This exercise will allow establishing hypotheses for its empirical contrast. The studies selected to be conceptualized by the theories put forward have found temporary differences in terms of resources, establishment of immigration as a central theme of the public agenda and justification of the political authoritarianism of the host country, the concentration of migrants in tourist areas, the majority expulsion of Mexican migrants to the United States, the adaptation of migrants to the family planning system, the establishment of differences between migrants and residents regarding marginalization, segregation, assimilation and integration, the Mexican migrant's self-concept towards the Spanish culture, the between violence, depression and self-efficacy and differences between men and women regarding socialization with the culture of the country that received them (Domínguez and Fuentes, 2006).

The objects of study are focused on a different trajectory. negative; poverty, immigration, marginalization, segregation, violence and depression. This route can be explained from the budgets of a vicious circle in which the accumulated stress indicates a socially destabilizing impact on the dynamics of organizations, groups and individuals in both the sending countries and receiving countries of migrants. The first case explains the migration and the second the return of the migrant. A positive trajectory; family, integration, socialization, self-concept, and self-efficacy. This process is a virtuous circle that job satisfaction is latent and is determined from family dynamics up individual capabilities through demands, organizational resources and work culture (Salanova and Schaufeli, 2009).

In these topics the perceptions of the actors are present since it is the appreciation of poverty that drives migrants to seek employment in countries in which greater and better employment, integration and self-efficacy opportunities are attributed to them, although they are also built scenarios of immigration, marginalization, segregation, 
violence and depression due to the opportunity cost of leaving a family, or the journey that migrants go through before settling down.

In this way, studies related to migration in the workplace can be schematized from the objects of study and the findings in reference to perceptions and behaviors.

The state of knowledge, in its negative trajectory of factors inherent in migration, begins with the perception of framing that would explain the perception of poverty associated with immigration that implies insertion in a recipient country. Then, the marginalization or segregation expected by not having documentation or technical specialty that supposes a better paid job. Once inserted into an organization, violence and depression would be other aspects perceived by migrants when interacting with xenophobic groups (Dominguez and Fuentes, 2006).

In its positive trajectory, migration would be driven by family networks that not only integrate the migrant to a job, but socialize their values, knowledge and skills in order to increase or reduce the self-concept of the group to focus the capacities in a shared paid activity for support networks.

Both trajectories can be broken down into hypotheses of dependency relations between the perceptions alluded to in order to explain the variability that the search for employment implies.

If risks are cultivated, mediated and framed to justify anti-migrant policies, labor deregulation as well as occupational conditions, the relationship between job search and the perception of demands and resources ex-explained through the perception of opportunities and capabilities. This is because the job search involves a willingness to risk, but depending on the expected opportunities and perceived abilities (Contreras, 2012).

In a similar process, the perception of capacities is the result of the cultivation, mediatization and framing of risks, which, when interacting with perceptions of demands, resources and opportunities, explain the virtuous circle of job search.

If the risks are cultivated, mediated and framed, then they reflect the social environment. If the relations between the groups are determined by the asymmetries between urbanity and rurality, as well as the inhibition of the migrant groups in favor of the resident groups, then it would warn about a context of demands greater than the available resources and therefore the exacerbation of the perception of risks (Berrou and Combaunous, 2012). 
In contrast to the perception of risks, the perception of opportunities is the result of perceptions of framing of information related to a high availability of resources. In a situation of scarcity of resources, labor demands tend to increase since the lack of technology is corrected with the management of tacit knowledge. Thus, individuals tend to perceive an increase in labor demands as their perception of framing is influenced by information related to the scarcity of resources (Carreón, 2016).

In the same way the impact of information related to the abundance of resources, the perception of framing will affect the perceptions of demands and then on the perceptions of resources. This means that when organizations are exposed to a contingency, the surrounding information defines the quantitative assessments of demands and resources (Bahamonde, 2013).

However, migrant groups not only adapt or assimilate the norms of a different group to them, they also socialize their capacities. In this way, acculturation coexists with multiculturalism. That is increased demands impinging on increasing their capacity and strengthening their job search strategy. In effect, the dynamic of the groups around former immigrants seems to complement the construction of risks, the establishment of topics, the framing of news, urban and rural asymmetries, the assimilation of risks, group asymmetries, the motivation of skills, the imbalance between demands and resources, orientation to work equilibrium, autonomy group and contingency strategies (Castiglioni et al. 2015).

However, the relationship between job search, perception of skills, perceived demands and perceived framing does not fit the two negative and positive trends of the state of knowledge. It is a process that goes through the vicious circle that is the search for vacancies from the increase in perceived abilities caused by the increase in risks and the demands spread as barriers. Or, it goes through the virtuous circle of self-employment strategies, work skills, opportunities and resources framed in news of progress.

It is necessary to contrast the hypotheses of the relations between migrant groups with a high educational level which could be closer to the positive process and migrant groups with low educational level more affected by the negative process in reference to other resident groups such as; officials, microentrepreneurs, merchants, farmers or 
transporters to clarify the specified relations to crisis or economic prosperity.

In this way, the meanings around the migration, crossing and return in reference to the opportunities and labor capacities of the locality will allow to notice two scenarios; 1 ) the power of the State over citizenship and, 2) the influence of migrant groups over ex-migrant groups. That is to say, the impact of the policies of business promotion and job creation would directly affect the evaluation of the authorities and programs of employment, subsidy or unemployment insurance that would complement the explanatory model. In addition, the discourses of migrant groups as symbols of the imaginary of ex-migrant groups.

Therefore, the search for employees or former migrants is an effect of migration times and spaces, the intensive diffusion of the labor market in television, the establishment of migration issues in Mexico and the United States, the causal attribution of risks in news programs and the urban-field relationship; cause of threats to resident groups and social segregation; synonymous with service capabilities, resolution of increased demands and scarce resources and compensation factor at work. It involves two processes; a negative one in which the demands of the labor market increase the risks and these must be mitigated by the capacities of migrants, another positive one in which the scarcity of resources must also be faced from the migrant skills. It is determined by the perceived capacities provided that these are affected by the perception of demands and the perceived framings of the market. However, it is necessary to carry out comparative studies to establish differences between migrant and resident groups in adverse or prosperous economic situations.

What are the relationships between educational, economic, situational, group and individual factors that determine the employment and occupation of former migrants in Xilitla, Huasteca region of San Luis Potosi (Mexico) during the period from September 2012 to March 2018.

The supposed relations of dependence between the perceptual factors that determine the search for employment in former migrants will be adjusted to the data obtained since the six hypotheses put forward are imbricated in a framework logic of the labor market that impacts the demands, resources, risks, opportunities and capabilities in order to predict occupational self-management. 
The supposed relations of dependence between the perceptual factors oriented to explain the job search will be different from the data to be observed since these will derive from a logic of collaborative networks in which trust, commitment, satisfaction and happiness are its central elements since family dynamics seems to have a greater impact than the framing logic of the labor market.

\section{METHOD}

Because it is a case study with no background, a non-probabilistic exploratory study was carried out with the majority of the local workforce.

Design. A cross-sectional study was carried out from September 2012 to March 2018 in Xilitla, Huasteca region of San Luis Potosi, Mexico.

Sample. A non-probabilistic selection of 147 former migrants was carried out. The inclusion requirements were related to experiences of crossing, stay and return in the national, regional or international labor market with the purpose of seeking employment opportunities and remunerations superior to those offered by the local labor market.

Sociodemographic. We interviewed 87 men $(\mathrm{M}=36.8$ years and SD $=9.27$ years $)$ and 60 women $(\mathrm{M}=27.4$ years and $\mathrm{SD}=4.58$ years $)$.

Socioeducative 25 percent of men completed the baccalaureate, 55 percent secondary, 15 percent primary and five percent had no studies completed. 47 percent of the women finished the baccalaureate, 36 percent the secondary and 17 percent the primary.

Psychological partner. 62 percent of respondents indicated that helping or supporting their family economically was the reason why they decided to emigrate, while 24 percent indicated that they wanted to know other places and ways of working different from the options of their locality. Finally, 14 percent answered that they wanted to buy some good or heritage for him or her.

Partner networks. 78 percent stated that a friend or family member encouraged them to migrate, 22 percent indicated that they were informed in the media about the risks and opportunities to work in the place where they worked.

Spatial partner. 41 percent said they were in a city in the United States, 32 percent said they work on the border between Mexico and the United States, 20 percent said they emigrated to Mexico, the Fed- 
eral District and seven percent were in San Luis Potosi, capital of the state with the same name.

Socioeconomic. It should be noted that the minimum wage in the Huasteca region is equivalent to USD200.13 per month and the respondents answered that in the place where they emigrated they had a higher salary than they could have had in the local labor market. Thus, 56 percent of men were employed in the services sector ( $\mathrm{M}=700.25$ USD monthly and SD $=14.82$ USD), 35 percent in the construction sector ( $\mathrm{M}=120.25$ USD and SD $=35.12$ USD) and 19 percent in trade ( $M=602.13$ USD and $S D=15.27$ USD). In the case of women, 72 percent were employed in domestic tasks $(\mathrm{M}=502.47$ USD and $\mathrm{DE}=10.26 \mathrm{USD}), 22$ percent in the industry $(\mathrm{M}=406.25 \mathrm{USD}$ and $\mathrm{DE}=24,1 \mathrm{USD})$ and six percent in commerce ( $\mathrm{M}=385.14$ USD and DE $=20.1$ USD).

Instrument. Built Scale Perceptions Labor (see Table 1).

Process. The snowball technique was used to identify former migrants considering crossing, stay and return as the preponderant characteristics of the survey. Once the sample was identified, they were visited at home and informed that the study was not related to any social program of government, religious association or political party. They were given the self-report while they were told they had about 25 minutes to respond. In cases where the response was systemacally the same or its absence, the respondents were asked to write the reasons why they had chosen the same answer, or had abstained from it. The data collected were captured in the Program of Statistics for Social Sciences (SPSS for its acronym in English) and software Analysis of Structural Moments (AMOS for its acronym in English) both in their versions 21.

The kurtosis parameter was used to establish the normal distribution, the alpha statistic of Cronbach to estimate the internal consistency, the KMO value for the adequacy, chi square for sphericity, factorial weight obtained from the exploratory factor analysis of principal components with varimax rotation and maximum likelihood to indicate the construct validity, the parameter phi for covariances, the gamma and beta statistics to estimate the dependence relations between exogenous factors and endogenous factors, or, between endogenous factors. In addition, the parameters sigma and epsilon were used for measurement errors and dist u $\mathrm{r}$ bio. With respect to the adjustment, the 
goodness of fit indexes (GFI) were used. Finally, the mean residual index (RMR) was calculated for the contrast of the null hypothesis.

Normal. The values of kurtosis close to the unit were assumed as evidence of normal distribution since they identify the tendency of the response in reference to the mean and the standard deviation. In the case of reagents with values higher than a value of five, they were eliminated from further analysis.

Table 1: Operationalization of variables

\begin{tabular}{|c|c|c|c|}
\hline Variable & Definition & Items & Options \\
\hline $\begin{array}{l}\text { Perception } \\
\text { of framing }\end{array}$ & $\begin{array}{l}\text { Degree of causal } \\
\text { attribution of } \\
\text { unemployment or } \\
\text { employment }\end{array}$ & $\begin{array}{l}\text { PE1, PE2, } \\
\text { PE3, PE4 PE5 }\end{array}$ & $\begin{array}{l}0=\text { nothing related, } 1= \\
\text { very little related, } 2= \\
\text { little related, } 3=\text { very } \\
\text { related }\end{array}$ \\
\hline $\begin{array}{l}\text { Claims } \\
\text { perception }\end{array}$ & $\begin{array}{l}\text { Level of demands of } \\
\text { the labor market }\end{array}$ & $\begin{array}{l}\text { PD1, PD2, } \\
\text { PD3, PD4, } \\
\text { PD5 }\end{array}$ & $\begin{array}{l}0=\text { never, } 1=\text { almost } \\
\text { never, } 2=\text { almost } \\
\text { always, } 3=\text { always }\end{array}$ \\
\hline $\begin{array}{l}\text { Resource } \\
\text { perception }\end{array}$ & $\begin{array}{l}\text { Degree of training and } \\
\text { technology that the } \\
\text { labor market offers }\end{array}$ & $\begin{array}{l}\text { PRE1, PRE2, } \\
\text { PRE3, PRE4, } \\
\text { PRE5 }\end{array}$ & $\begin{array}{l}0=\text { never, } 1=\text { almost } \\
\text { never, } 2=\text { almost } \\
\text { always, } 3=\text { always }\end{array}$ \\
\hline $\begin{array}{l}\text { Perception } \\
\text { of risks }\end{array}$ & $\begin{array}{l}\text { Level of obstacles } \\
\text { attributable to the } \\
\text { labor market }\end{array}$ & $\begin{array}{l}\text { PRI1, PRI2, } \\
\text { PRI3, PRI4, } \\
\text { PRI5 }\end{array}$ & $\begin{array}{l}0=\text { never, } 1=\text { almost } \\
\text { never, } 2=\text { almost } \\
\text { always, } 3=\text { always }\end{array}$ \\
\hline $\begin{array}{l}\text { Perception } \\
\text { of } \\
\text { opportunit } \\
\text { ies }\end{array}$ & $\begin{array}{l}\text { Estimation of sales } \\
\text { based on a calculation } \\
\text { of labor market needs }\end{array}$ & $\begin{array}{l}\text { P01, P02, } \\
\text { P03, P04, } \\
\text { P05 }\end{array}$ & $\begin{array}{l}0=\text { not at all frequent, } 1 \\
=\text { very rare, } 2=\text { rare, } 3= \\
\text { very frequently }\end{array}$ \\
\hline $\begin{array}{l}\text { Perception } \\
\text { of } \\
\text { capabilities }\end{array}$ & $\begin{array}{l}\text { Level of skills, } \\
\text { knowledge and values } \\
\text { to enter the labor } \\
\text { market }\end{array}$ & $\begin{array}{l}\text { PC1, PC2, } \\
\text { PC3, PC4, } \\
\text { PC5 }\end{array}$ & $\begin{array}{l}0=\text { not at all frequent, } 1 \\
=\text { very rare, } 2=\text { rare, } 3= \\
\text { very frequently }\end{array}$ \\
\hline Job search & $\begin{array}{l}\text { Type of strategy to } \\
\text { insert in the labor } \\
\text { market }\end{array}$ & $\begin{array}{l}\text { BE1, BE2, } \\
\text { BE3, BE4, } \\
\text { BE5 }\end{array}$ & $\begin{array}{l}0=\text { nothing, } 1=\text { talk to } \\
\text { strangers, } 2=\text { use the } \\
\text { Internet, } 3=\text { talk to } \\
\text { family and friends }\end{array}$ \\
\hline
\end{tabular}

Source: self-made.

Validity. The KMO value greater than 0.60 was assumed as evidence of the adequacy of the responses to the factors. $\mathrm{Cu}$ chi value to near unity and meaningful was considered as evidence of sphericity of responses regarding factors. Finally, the factorial weight greater than 0.300 was assumed as evidence of correlation between the item and the factor. In the cases in which the values were lower than the required thresholds, or in their case, they were not significant, they were 
dismissed from further analysis. Regarding the explained variance higher than 20 percent for each factor was considered as a requirement for the acceptance of the null hypothesis.

Reliability. An alpha value greater than 0.60 and lower than 0.90 was assumed as evidence of internal consistency. In those cases, in which the correlation between item and scale was less than 0.60 , it was assumed to be a spurious relationship while a value greater than 0.90 was considered as a collinear relationship. Both relations, spurious and collinear allowed to discard items from the following analyzes.

Covariation The phi value, like the alpha value, which ranged between 0.30 and 0.90 was used as evidence of associative relationship between two factors considering the other factors. In cases where the values were lower than 0.30 or higher than 0.90 were used to guide the interpretation of results.

Structure. The gamma and beta values as well as the phi values were used as evidence of spurious relationship, dependence relationship or collinear relationship. In this way, following the threshold used, the dependency relationship model was interpreted considering the values between 0.30 and 0.90

Adjustment. The GFI value close to the unit was assumed as evidence of adjustment of the model of specific relationships in contrast to the model of estimated relationships. The value less than 0.90 was assumed as acceptance of the alternative hypothesis while the value greater than 0.90 was considered as evidence of acceptance of the null hypothesis.

Residual. The RMR value close to zero was assumed as evidence of adjustment of the dependency ratios specified in comparison to the estimated dependency ratios. This implied the acceptance of the null hypothesis and the rejection of the alternative hypothesis. However, the RMR value higher than 0.10 was assumed as evidence of rejection of the null hypothesis and acceptance of the alternative hypothesis.

\section{RESULTS}

Table 2 shows the descriptive data of the instrument.

Regarding the perception of framing, the descriptive data show a tendency of the items to the option "very little related". The R5 $(M=2.84$; $S=0.35 ; K=1.08)$ approached item option "bit related" while item R1 ( $M=1.03, S=0.38 ; K=1.02)$ exemplified the "very little related» option. This means that the framing of the media regarding events 
in the US and Mexico seems to have a lesser impact on the sample surveyed since the perception of framing tends to concentrate on an option that indicates low credibility.

Regarding the perception of demands, items R6 $(M=2.49, S=0.62$; $K=1.05)$ and $\mathrm{R} 9(M=2.95, S=0.49 ; K=1.01)$ with lower and higher scores show the tendency of the responses towards the "almost always" option. This means that the labor market is perceived as a consistent demand scenario for the surveyed sample.

In contrast, the perception of resources, according to the items R13 $(M=1.06, S=0.64, C=1.09)$ and the item R15 $(M=1.01, S=0.33$; $C=1.05$ ), approached the "almost never" option. That is, the sample surveyed not only considers that the labor market demands more and more, but also considers that the resources available to it are increasingly scarce.

However, although the relationship between demands and perceived resources is the reverse, risk perception presents a trend of the extreme items R17 $(M=1.02, S=0.63, K=1.01)$ and R20 $(M=1.04$, $S=0.82, K=1.09$ ) contrary to the scarcity of resources and increased demands. The sample surveyed seems to consider that the increase in demands and the reduction of resources are insufficient to anticipate a scenario of health risks.

Precisely, the perception of opportunities complements the assumption according to which the surveyed sample ignores the consequences of the increase in demands and the decrease in resources. The items R22 $(M=2.48, S=0.51, K=1.05)$ and R25 $(M=2.91, S=0.22, K$ $=1.05$ ) show the tendency of the responses to the "always" option This is because the survey sample seems to anticipate a scenario in which risks are minimal and opportunities are abundant.

When observing the perception of abilities, the items R27 $(M=$ 2.48, $S=0.51, K=1.05)$ and R30 $(M=2.91, S=0.22, K=1.04)$ they complement the scenario of risks and opportunities in contrast to the scenario of demands and resources. The sample surveyed seems to consider that "very frequently" their capacities will allow them to face the two scenarios that they perceive. 
Table 2: Instrument descriptions

\begin{tabular}{|c|c|c|c|c|c|c|c|c|c|c|c|}
\hline$R$ & Scale / Item & M & $S$ & $\mathbf{K}$ & F1 & F2 & F3 & F4 & F5 & F6 & F7 \\
\hline & $\begin{array}{l}\text { Perceptions of } \\
\text { frames }(56 \% \text { of } \\
\text { variance, alpha }=0.71)\end{array}$ & & & & & & & & & & \\
\hline $\begin{array}{r}r \\
1\end{array}$ & $\begin{array}{l}\text { "The economic recession } \\
\text { of the US" and } \\
\text { "Unemployment in } \\
\text { Mexico" are: }\end{array}$ & 1.03 & 0.38 & 1.02 & & & & & & & \\
\hline $\begin{array}{l}r \\
2\end{array}$ & $\begin{array}{l}\text { "Trumps's immigration } \\
\text { policy" and "Mexico's } \\
\text { economic crisis" are: }\end{array}$ & 1.05 & 0.49 & 1.03 & 0.371 & & & & & & \\
\hline $\begin{array}{l}r \\
3\end{array}$ & $\begin{array}{l}\text { "The economic crisis in } \\
\text { Mexico" and "The US } \\
\text { border police" are: }\end{array}$ & 1.06 & 0.19 & 1.04 & 0.380 & & & & & & \\
\hline $\begin{array}{l}r \\
4\end{array}$ & $\begin{array}{l}\text { "The railroad the beast" } \\
\text { and "The death of Central } \\
\text { Americans" are: }\end{array}$ & 2.71 & 0.23 & 1.06 & 0.485 & & & & & & \\
\hline $\begin{array}{l}r \\
5\end{array}$ & $\begin{array}{l}\text { "Unemployment in the } \\
\text { US" and "Wages in } \\
\text { Mexico" are: }\end{array}$ & 2.84 & 0.35 & 1.08 & 0.401 & & & & & & \\
\hline & $\begin{array}{l}\text { Perceptions of demands } \\
\text { ( } 41 \% \text { of variance, alpha } \\
=0.74)\end{array}$ & & & & & & & & & & \\
\hline $\begin{array}{l}r \\
6\end{array}$ & $\begin{array}{l}\text { The jobs in the US } \\
\text { maquiladoras are "heavy" }\end{array}$ & 2.49 & 0.62 & 1.05 & 0.261 & & & & & & \\
\hline $\begin{array}{l}r \\
7\end{array}$ & $\begin{array}{l}\text { In Mexico security works } \\
\text { are "rough" }\end{array}$ & 2.79 & 0.16 & 1.08 & & & & & & & \\
\hline $\begin{array}{c}r \\
8\end{array}$ & $\begin{array}{l}\text { In the US sales work is } \\
\text { "calm" }\end{array}$ & 2.71 & 0.72 & 1.03 & & & & & & & \\
\hline $\begin{array}{l}r \\
9\end{array}$ & $\begin{array}{l}\text { Cleaning jobs in Mexico } \\
\text { are "heavy" }\end{array}$ & 2.95 & 0.49 & 1.01 & & 0.304 & & & & & \\
\hline $\begin{array}{l}r \\
1 \\
0\end{array}$ & $\begin{array}{l}\text { In the US domestic work is } \\
\text { "tired" }\end{array}$ & 2.58 & 0,52 & 1.06 & & 0.461 & & & & & \\
\hline & $\begin{array}{l}\text { Perceptions of resources } \\
(37 \% \text { of variance } \\
\text { and alpha }=0.75)\end{array}$ & & & & & & & & & & \\
\hline $\begin{array}{l}r \\
1 \\
1\end{array}$ & $\begin{array}{l}\text { In the US they give you a } \\
\text { Smartphone to sell the } \\
\text { products / services }\end{array}$ & 1.04 & 0.47 & 1.07 & & 0,261 & & & & & \\
\hline $\begin{array}{l}r \\
1 \\
2\end{array}$ & $\begin{array}{l}\text { In Mexico you are trained } \\
\text { for the " change " of } \\
\text { products }\end{array}$ & 1.05 & 0,52 & 1.07 & & 0.362 & & & & & \\
\hline $\begin{array}{l}-r \\
1 \\
3\end{array}$ & $\begin{array}{l}\text { The "patterns" of } \\
\text { construction in the US } \\
\text { lend you the tools }\end{array}$ & 1.06 & 0.64 & 1.09 & & & & & & & \\
\hline $\begin{array}{l}r \\
1 \\
4\end{array}$ & $\begin{array}{l}\text { In sales jobs in Mexico } \\
\text { they only give you } \\
\text { uniform }\end{array}$ & 1.02 & 0.61 & 1.03 & & & 0.385 & & & & \\
\hline $\begin{array}{l}r \\
1 \\
5\end{array}$ & $\begin{array}{l}\text { In the US restaurants the } \\
\text { workers speak English }\end{array}$ & 1.01 & 0.33 & 1.05 & & & 0.380 & & & & \\
\hline
\end{tabular}

$\mathrm{R}=$ Reactive, $\mathrm{M}=$ Median, $\mathrm{S}=$ Standard Deviation, $\mathrm{K}=$ Kurtosis, $\mathrm{A}=$ Alpha wjth excluded value item. Method: Pringipal ways; Rotation: Promax. Adecuation \& Sphericity $\Upsilon_{\chi 2}=23,24$ (21df) p $<, 05 ; \mathrm{KMO}=, 070$ J

Source: Prepared with the study data. 
Table 2: Instrument descriptions

(Continue)

\section{Perceptions of risks}

(34\% of variance, alpha = 0.77)

$\boldsymbol{r}$ Assaults on stores in

$\begin{array}{lll}1.02 & 0.41 & 1.07\end{array}$

0,271

1 Mexico are with "pistol in

6 hand"

$r$ English is necessary to sell

1 in the US

$\begin{array}{lll}1.02 & 0.63 & 1.01\end{array}$

0,241

7

$\begin{array}{llllll}\boldsymbol{r} & \text { In Mexico they pay with } & 1.07 & 0.78 & 1.02 & 0.31\end{array}$

1 counterfeit money

8

$\boldsymbol{r}$ In the US the migra

$\begin{array}{lll}1.03 & 0.41 & 1.07\end{array}$

1 watches the constructions

9

$\boldsymbol{r}$ The "patrones" in Mexic

$\begin{array}{llll}1.04 & 0.82 & 1.09 & 0.331\end{array}$

2 pay on different days

$\boldsymbol{0}$

Perceptions of opportunities $(27 \%$ of variance, alpha $=0.76$ )

$r$ In the US, anything to eat

2 is sold

1

$r$ Fast food is a safe sale in

$\begin{array}{lll}2.52 & 0.94 & 1.00\end{array}$

2 Mexico

2

2 to sell anything

3

$\boldsymbol{r}$ Anything that looks like

2 drink is consumed in

4 Mexico

$r$ The "Americans" buy

2 anything that looks like

5 crafts

Perceptions of abilities (23\% of variance, alpha $=0.70$ )

$r$ I can have more than one

$2.48 \quad 0,51 \quad 1.05$

$2.68 \quad 0.31 \quad 1.06$

0.210

$2.75 \quad 0.54 \quad 1.01$

0.467

$2.71 \quad 0.68 \quad 1.06$

0.391

2 job a day in the US

In Mexico I can sell

anything to eat

7

2 the "migra" of the EU

8

r I can "put up with work"

2 in Mexico's maquiladoras

9

$r$ In the US, I can "endure"

3 the work in construction

$\begin{array}{lll}2.83 & 0.20 & 1.07\end{array}$

0.415

$\begin{array}{lll}2.40 & 0,51 & 1.03\end{array}$

0.352

$2.51 \quad 0.36 \quad 1.06$

0,244

$\begin{array}{lll}2.71 & 0.40 & 1.02\end{array}$

0,576

$2,66 \quad 0,55 \quad 1,04$

$\mathrm{R}=$ Reactive, $\mathrm{M}=$ Median, $\mathrm{S}=$ Standard Deviation, $\mathrm{K}=$ Kurtosis, $\mathrm{A}=$ Alpha with excluded value item. Method: Principal ways; Rotation: Promax. Adecuation \& Sphericity $\chi 2=23,24$ (21df) p $<, 05 ; \mathrm{KMO}=, 070 \mathrm{~J}$

Source: Prepared with the study data. 
Table 2: Instrument descriptions

(Continue)

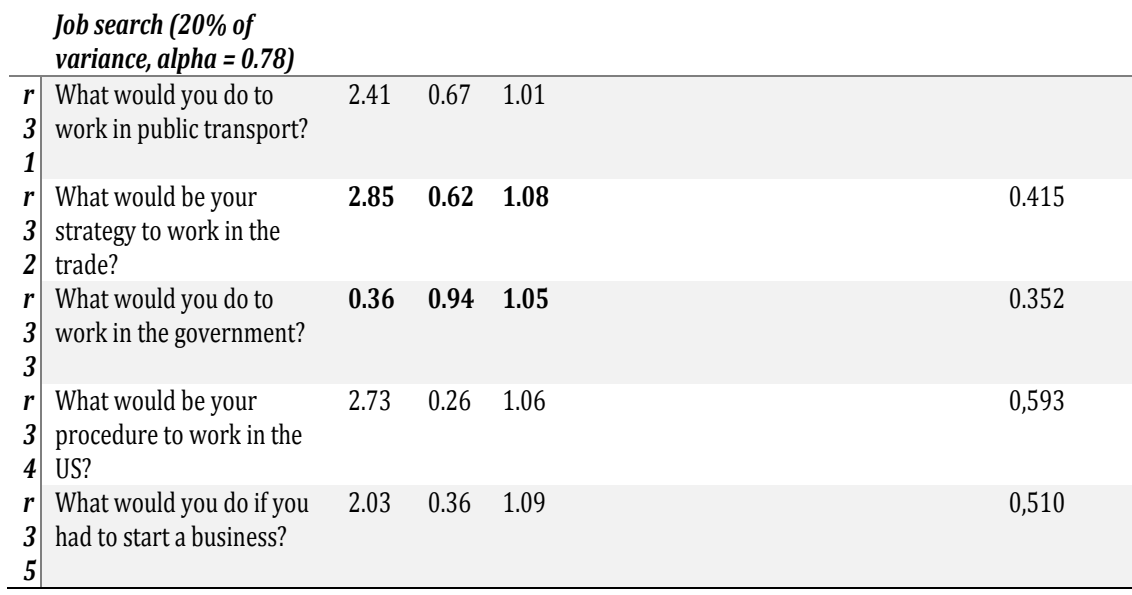

$\mathrm{R}=$ Reactive, $\mathrm{M}=$ Median, $\mathrm{S}=$ Standard Deviation, $\mathrm{K}=$ Kurtosis, $\mathrm{A}=$ Alpha with excluded value item. Method: Pringipal ways; Rotation: Promax. Adecuation \& Sphericity $\gamma_{\chi 2}=23,24$ (21df) p $<, 05 ; \mathrm{KMO}=, 070$ J

Source: Prepared with the study data.

Finally, regarding the search for employment, the surveyed sample oscillates between not having a strategy to work in the government item R33 $(M=0.36, S=0.94, K=1.05)$ and talking to their relatives to start a business item R32 $(M=2.85, S=0.62, K=1.08)$ this means that the scenario derived from the relationship between demands and resources would be adjusted to the inaction of job search in the government, while the scenario related to risks, opportunities and capabilities would be oriented to the management of a business among their relatives.

The descriptive data of the instrument reveal two perceived scenarios that, when related to the job search, could be complemented. However, the consistency of the sample responses and their validity would open up the possibility of establishing dependency relationships between the perceived scenarios and the search for employment.

Table 2 shows suitability analysis (KMO $=6.06)$ and sphericity $\left(\mathrm{X}^{2}=3.57\right.$ (14 gl) $\left.\mathrm{p}=0.001\right)$ which allowed to perform the estimation of seven factors. The first factor related to the perception of framing explained 56 percent of the variance and included the items R1, R2, $\mathrm{R} 3$ and R4 to reach an internal consistency of 0.71 above the required threshold. The second factor alluding to the perception of demands ex- 
plained 41 percent of the variance and was configured with indicators R7, R8 and R10, in addition it obtained a reliability of 0.74 higher than the minimum required.

The third factor regarding the perception of resources explained 37 percent of the variance whose reagents were R11, R12, R14 and R15 which were consistently related to the scale (alpha $=0.75)$. The fourth factor related to risk perception explained 34 percent of the variance while it was configured with the items R16, R17, RI8 and R20 which reached a reliability above the specified threshold (alpha $=0.77$ ). The fifth factor related to opportunities explained 27 percent of the variance when correlating with items R21, R22, R23 and R25, which obtained an optimal internal consistency $(a l p h a=0.76)$. The sixth factor involved was the perception of capacities that explained 23 percent of the variance and was constructed with reagents R26, R27, R28, R29 and R30 that correlated favorably with the instrument (alpha $=0.70$ ). Finally, the seventh factor referred to the job search that explained 20 percent of the variance and was configured with indicators R32, R34 and R35 when consistently correlating with the scale (alpha $=0.78$ ).

The validity and reliability of the instrument evidenced seven factors consistent with the manifest variables. This supposed associative relations between each factor. In this sense, Table 3 shows the analysis of covariance between the perception of framing and the search for employment ( $\Phi=0.694$ ) with respect to the other factors. In the same way, the perception of demands was associated with the perception of resources $(\Phi=0.762)$. In the case of the perception of resources, the correlation with the perception of risks $(\Phi=0.601)$ was greater with respect to the other factors. On the other hand, this last factor of perceived risks was positively linked to the search for employment $(\Phi=0.681$ ) in reference to the other factors. Finally, the perception of opportunities was related to the job search $(\Phi=0.795)$. These results show associative relationships between the factors involved with respect to the correlation between the other factors. From these findings it was possible to expect dependency relationships.

Capacity to determiner work strategies $(\beta=0.57)$ corroborated the hypothesis 1 , but the factor which achieved greater correlation value was perceived opportunities ( $\Phi=0.795$ ). That is, the sample surveyed seems to opt for their perceived skills more than for the labor market opportunities when establishing a job search strategy (see Figure 5). 
Regarding hypothesis 3, the risk perception was influenced by the perception of framing $(\gamma=0.62)$ same variable with which it established a higher covariance $(\Phi=0.485)$ in reference to the perception of demands ( $\Phi=0.395$ ), but lower than the search for employment, a factor with which it was associated to a greater extent ( $\Phi=0.681)$.

For its part, hypothesis 4 was not contrasted since both predictors; framing perception $(\gamma=0.57)$ and perception of resources $(\gamma=$ 0.50 ) were related spuriously. Despite this, the search for employment was associated to a greater extent $(\Phi=0.694)$ with respect to the other factors.

Finally, in scenario five and six, the perception of framing determined the perception of demands $(\gamma=0.39)$ and the perception of resources $(\gamma=0.48)$, although the perception of resources was associated to a greater extent with the perception of demands ( $\Phi=0.762$ ) and the perception of risks covaried mainly with the perception of resources $(\Phi=0.601$ ) in comparison to the other factors.

The analysis of dependency relations suggests the acceptance of hypotheses 1, 2, 3, 5 since hypothesis four could not be contrasted. The findings allowed us to estimate the square chi $\left[\mathrm{X}^{2}=3.48(3 \mathrm{gl}) \mathrm{p}=\right.$ 0.000], the Adjustment Goodness Index (GFI $=0.975$ ) and the Quadratic Mean Residual (RMR $=0.001$ ) which tested the hypothesis null and whose value is allowed to accept it.

Table 3: Correlations \& covariance between factors

\begin{tabular}{|c|c|c|c|c|c|c|c|c|c|c|c|c|c|c|c|c|}
\hline & $M$ & $S$ & $F 1$ & F2 & F3 & F4 & F5 & F6 & $F 7$ & $F 1$ & $F 2$ & F3 & $F 4$ & F5 & $F 6$ & F7 \\
\hline$F 1$ & 23,41 & 12,34 & 1,0 & & & & & & & 1,8 & & & & & & \\
\hline F2 & 32,25 & 15,42 &, $41^{* *}$ & 1,0 & & & & & & .45 & 1,9 & & & & & \\
\hline F3 & 24,39 & 16,58 &, $50^{*}$ &, $58^{*}$ & 1,0 & & & & & .39 & .76 & 1,9 & & & & \\
\hline F4 & 26,43 & 10,59 &, $67^{*}$ &, $47^{*}$ &, $30^{* *}$ & 1,0 & & & & .48 & .39 & .60 & 1,8 & & & \\
\hline F5 & 21,46 & 19,83 &, $47^{* *}$ &, $40^{*}$ &, $48^{* * *}$ & ,39* & 1,0 & & &, 59 &, 59 & .39 &, 51 & 1,8 & & \\
\hline F6 & 32,47 & 15,47 &, $38 *$ &, $52^{*}$ &, $52^{*}$ &, $48^{* *}$ & ,60* & 1,0 & & .39 &, 49 & .40 & .50 & .50 & 1,7 & \\
\hline F7 & 43,54 & 13,58 &, $56^{* * *}$ &, $48^{* *}$ & ,68* &, $51^{* *}$ &, $56^{*}$ &, $42^{*}$ & 1,0 & 69 & .50 & .40 & .68 & .79 & .33 & 1,9 \\
\hline
\end{tabular}


Figure 5: Structural equation modelling
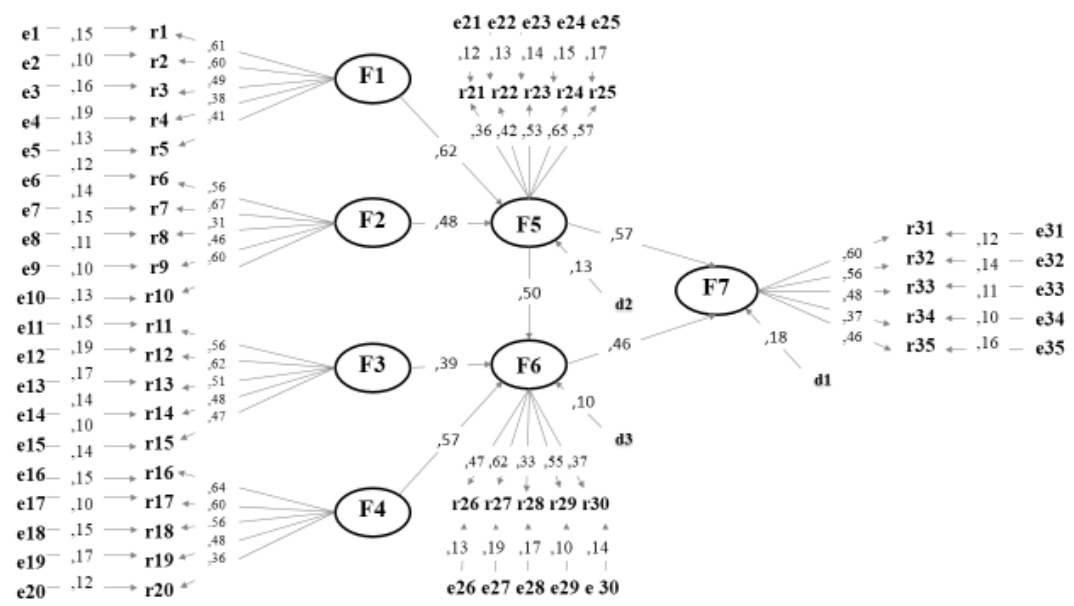

Source: Elaborated with data study.Regarding hypothesis 2 , the perception of abilities correlated with the perception of risks $(\Phi=0.506)$, but the perception of demands was determined ( $\beta$ $=0.46$ ). This means that the survey sample seems to trust your s capabilities when seeking employment, although there is an increase in labor market demands and risks associated with skills which delineates the relationship between their abilities and search strategies vacancy.

The present study has established five hypotheses regarding the prediction of job search in a sample of migrants. The results warn that the perceived abilities determined the search strategies, although the perceived demands affected the labor skills.

The first hypothesis regarding the prediction of the search for employment based on the perception of abilities $(\beta=0.57)$, the latter was influenced by the perceived demands $(\gamma=0.62)$ as a second contrasted hypothesis. The third hypothesis was established by the incidence of the perception of framing on perceived risks $(\gamma=0.48)$ while both the perception of demands and the perceived resources were determined by the perceived framing of the labor market $(\gamma=0.57)$ in assumptions five and six.

Finally, the null hypothesis was accepted since the statistic values as well as the adjustment and residual indices showed the contrast between the specified relationships and the observed data $\left[\mathrm{X}^{2}=3.48\right.$ $(3 \mathrm{gl}) \mathrm{p}=0.000 ; \mathrm{GFI}=0.975 ; \mathrm{RMR}=0.001$ ). 


\section{Discussion}

The objective of the present work was to contrast the perceptions around the governance of migratory flows considering seven dimensions related to framings, demands, resources, risks, opportunities, capacities and employment. In this sense, the reliability and validity of an instrument that measures the seven dimensions allowed to establish the relationships between these factors with respect to the job search in migrants, but the type of study, the type of selection shown and the type of analysis The statistical results limit the results of this study to the context and to the study sample.

It is necessary to carry out a quasi-experimental study with a probabilistic and stratified selection in order to be able to contrast the trajectories of dependency relationships between the variables used in the literature consulted. Such research will make it possible to establish an agenda centered on the propaganda of the State's rector as a bilateral negotiator for the expulsion and / or reception of migrants.

Having demonstrated the process of establishing the bilateral agenda in the analysis of media propaganda that would highlight the asymmetries between the quality of life of an expulsion context in relation to the social welfare of a receiving context, the conception of the Occupational health, including the salary amount and subsequent remittances, would generate a work identity that would activate travel, stay and return expectations in potential migrants with some capacity, skill or knowledge required in the receiving scenario and in accordance with the values and norms of the dominant native culture.

In the framework of the construction of a governance of migratory flows, co-management and co-responsibility would be the balance between the growing demands of the labor market with respect to the capacities of migratory flows and the resources of the host organizations. It would be a system of recruitment and selection of personnel in which migratory flows would participate through representatives in each of the government instances, but under the yoke of an intercultural conception that would oblige the receiving and expelling States to at least respect the economic, political, social and labor rights of migrants. 


\section{Conclusion}

The governance of migrant flows refers to a system of co-management and co-responsibility based on intercultural precepts of respect for the rights and individual guarantees of migrants in relation to a dominant indigenous culture, but the incidence in the expulsion and receiving policies would not be exclusively gestated. in the attention to vulnerable groups, labor conditions or their human rights, but also, it would be carried out in the process of establishing the bilateral agenda between the countries and organizations dedicated to promote propaganda of expulsion and reception of migrant flows, the adjustment of its uses and customs to the values and norms native, as well as to acceptance of occupational risks.

\section{BIBLIOGRAPHICAL REFERENCES}

Aldana, W. I.; C. García; A. Sánchez; J. Hernández; F. Espinóza and F. R. Sandoval. (2019). "Especificación de un modelo para el estudio de la identidad migratoria". Epsys, 30, 1-8 Disponible en http://epsys.com

Bahamond, E. P. (2013). "Attitudes of Chileans towards the acculturative orientations of Peruvian immigrants and their relationship with intercultural variables". Praxis Revista de Psicología, 15, pp. 29-55.

Berrou, JP. and F. Combaunous. (2012). "The personal networks of entrepreneurs in a informal African urban economy. Does the strength of ties matter?". Review of Social Economy, 1, pp. 1-30.

Caballlo, A.; R. Reyes and P. Solis. (2006). "The competitive strategy adopted by the transnational company in the global market". Accounting and Administration, 50, pp. 89-122.

Carreón, J. (2016). Human development: Governance and social entrepreneurship. Mexico: UNAM-ENTS.

Castiglioni, M., I. Castro y JL. Galán. (2015). "The use and choice of multipatner partnerships: an exploratory study". Market Economic \& Business Journal, 45(1), pp. 95-123. Disponible en http://dx.doi.org/10.7200/esicm.150.0461.2e

Castro, T. and Rosero, L. (2011). "Maternity and borders. The fertility of immigrant women in Spain". International Journal of Sociology, 1, pp. 105137.

Contreras, G. (2012). "Networking associations for the socio-digital integration in Andalusia". Journal of Andalusian Studies, 29, pp. 105-126. Disponible en http://dx.doi.org/10.12795/rea.2012.i29.05 
Delgadillo, L.; A. Vargas; Á. Nievar; J. Arguello and L. González. (2013). "Effects of partner violence on migrant women". Civilize, 13, pp. 103-116.

Delgado, M. A., C. García and S. Mejía. (2018). "Specification of a model for the study of consensual migration". Ehquidad, 9, 33-49. Disponible en http://dx.doi.org/10.15257/ehquidad.2018.0002

Domínguez, G. y J. Fuentes. (2006). "Communication and information as or generators of competitiveness in organizations". Accounting and Administration, 50, 207-230.

Farraguti, G. (2012). "Governmentality and human capital. Towards an outline of the emergency conditions of discourses on the information society, education and new technologies". Practices and Discourses, 1, pp. $1-16$.

Fernández, O. (2011). "Genesis and composition of an Ibero-American migratory system”. Nomads, 29, pp. 1-22.

García, C. (2018). "Coffee entrepreneurship among migrants of the Huazteca region central Mexico". E\&D, 30, pp. 119-147. Disponible en http:// dx.doiorg/10.19052/ed.4324

Guardiola, A., M. Espinar; E. Hernández and M. Sánchez. (2010). “The immigrants as a threat. Migratory processes in Spanish television". Convergence, 17, pp. 49-68.

Hernández, P. (2013). "The Costa Rican identity before the dilemmas of migration, cultural diversity and socioeconomic inequality". Reflections, 92, pp. 23-33.

López. Y. (2013). "Migration and ethnicity in the construction of imaginaries: The case of Mexicans in Murcia". Imagonauts, 3, pp. 37-55.

Manktelow, A. (2014). Guide to emerging markets. London: Economist Intelligence Unit.

Martínez, A. (2012). "Analysis of business networks and their territorial incidence. Technology transfer, learning and innovation". Journal of Andalusian Studies, 29, pp. 18-58. Disponible en http://dx.doi.org/10.12795/ rea.2012.i29.02

Mora, V.; T. Morales; P. Caballero and Ma. Rivera. (2013). "Migration of the spouse: Analysis of the psychological resources of Michoacan women". Uaricha, 21, pp. 44-55.

Pacheco, D. (2013). "The Costa Rican identity before the dilemmas of migration, cultural diversity and socioeconomic inequality". Reflections, 92, pp. 23-33.

Ramos, L. (2013). "Alliances and collaborative networks between the cultural groups of the ethnic arts in Andalucia". Empriia, 15, 26-34. Disponible en http://dx.doi.org/10.5944/empiria.26.7151 
Relative, JL. (2006). "The training of administrators in the new international environment". Accounting and Administration, 50, pp. 124-144.

Robles, C.; L.E. Alviter; A.O. Ortega and E. Martínez. (2016). "Culture of quality and innovation in the microenterprise". In M. Quintero., Sales, J. and Velázquez, EB (coord.). Innovation and technology Challenges for its practical application in companies. pp. 11-27. Mexico: Porrúa-UAEMEX.

Salanova, M. and W. Schaufeli. (2009). The engagement at work. When work becomes passion. Madrid: Alliance.

Sánchez, A.; F. Anguiano; H. D. Molina; L. A. Zallas; W. I. Aldana, G. Pérez, A. Quezada and C. García. (2018). "Categorial structure and subcategories in the exploration of press releases related to the administration of migratory security". IASF, 11(28) pp. 1-23.

Sánchez, A.; M. Juárez; J. M. Bustos and C. García. (2018). "Contrast a labor of expectations in ex migrants from central Mexico". GPT, 32, pp. 21-36.

Sosa, F. y E. Zubieta. (2012). "Psychological acculturation and beliefs in migrant and non-migrant students". Hologram, 17, pp. 45-70.

Ten, J. (2010). “Labor immigration in La Rioja”. Redur, 9, pp. 271-307.

US Census Bureau. (2017). "American community surveys". Washinting: USCB. Disponible en https://www.census.gov/

Zonj, J. y J. Batalova. (2019). Mexican inmigrants in the United States. Migration policy Institute. Disponible en https://www.migrationpolicy.org/ article/mexican-immigrants-united-states

\section{CURRICULAR SUMMARY OF THE AUTHORS}

\section{Francisco Espinoza Morales}

Doctor en Educación, Profesor Investigador de Tiempo Completo, Universidad de Sonora, campus Navojoa. Fundador de la Academic Transdisciplinary Network. Línea de investigación en "Gobernanza de la Formación del Capital Intelectual”. Evaluador, revisor y dictaminador en revistas internacionales e indexadas.

Dirección electrónica: http://orcid.org/0000-0002-4252-5893.

Dirección electrónica: fespinoz@navojoa.uson.mx

\section{Héctor Daniel Molina Ruíz}

Maestro en Ingeniería de Sistemas, UNAM. Profesor Investigador, Universidad Autónoma del Estado de Hidalgo. Editor en jefe de Revista Universitaria. http://orcid.org./0000-0001-6016-3889.

Dirección electrónica: m_en_i_molina_ruiz@engineer.com agcshdmr@hotmail.com hmolina@uaeh.edu.mx 
Rigoberto Sánchez Rosales

Doctor en Ciencias Económico Administrativas, profesor de Asignatura, Universidad Autónoma del Estado de México. Unidad Académica Profesional Huehuetoca. Academia de Actuaria. Línea de investigación en "Gobernanza de la Salud Migrante". Dirección electrónica: rigoberto_s_r@hotmail.com

\section{Arturo Sánchez Sánchez}

Doctor en Administración por la Universidad Nacional Autónoma de México, Facultad de Contaduría y Administración. Profesor de Tiempo completo en la Universidad Autónoma de Tlaxcala, adscrito al Sistema Nacional de Investigación. Línea de investigación en "Sistemas Gerenciales y Violencia Organizacional". http://orcid.org/0000-0002-49461559

Dirección electrónica: artuross1@hotmail.com

\section{Cruz García Lirios}

Estudios de Doctorado en Psicología Social y Ambiental, UNAM. Profesor de asignatura en la Universidad Autónoma del Estado de México, Unidad Académica Profesional Huehuetoca, Academia de Trabajo Social. Ha desarrollado la línea de investigación en cibercultura política. Editor, evaluador, revisor y dictaminador de revistas indexadas. http://orcid.org/0000-0002-9364-6796

Dirección electrónica: cgarcial213@profesor.uaemex.mx 